\title{
PENERAPAN METODE BACKGROUND SUBTRACTION DENGAN MENGGUNAKAN KANDIDAT SAMPLING BACKGROUND UNTUK DETEKSI KEMACETAN
}

\author{
Cipto Prabowo ${ }^{1}$ Zurnawita $^{2}$ \\ ${ }^{1}$ Teknologi Informasi, Politeknik Negeri Padang \\ ${ }^{2}$ Teknik Elektro, Politeknik Negeri Padang \\ Email: ${ }^{1}$ cipto@pnp.ac.id, ${ }^{2}$ zurnawita@pnp.ac.id
}

(Naskah masuk: 17 Oktober 2018, diterima untuk diterbitkan: 30 Oktober 2018)

\begin{abstract}
Abstrak
Penggunaan teknologi informasi untuk mengatasi kemacetan lalu lintas sudah banyak digunakan, salah satunya adalah dengan menggunakan CCTV. Citra dari CCTV diurai antara foreground (citra kendaraan, sebagai salah satu komponen penyebab kemacetan) dan backgroundnya (citra latar lalu lintas), fokus penelitian salah satunya adalah cara menentukan background model dengan berbagai macam teknik. Pada penelitian ini mencoba memberikan alternatif penentuan background model dengan menerapkan kandidat sampling background sebagai background model. Lokasi penelitan pada simpang bypass ketaping padang dan pengambilan gambar menggunakan raspberry pi dan web camera dengan arah tembakan menyamping dan durasi tembakan tiap menit. Hasil yang didapatkan cukup memuaskan terutama pada kondisi pagi dan siang hari.
\end{abstract}

Kata kunci: background model, simpang bypass ketaping padang, raspberry pi, web camera

\section{APPLIED BACKGROUND SUBTRACTION METHOD USED BACKGROUND CANDIDATE SAMPLING FOR CONGESTION DETECTION}

\begin{abstract}
The use of information technology to overcome traffic congestion has been widely used, one of them is by using CCTV. The image of CCTV is parsed between the foreground (vehicle image, as one of the components of the congestion cause) and the background (traffic background image), the focus of research is one way of determining the background model with various techniques. In this research try to give alternative background model determination by applying background sampling candidate as background model. Research location at intersection bypass ketaping and taking pictures using raspberry pi and web camera with sideways shot direction and duration of shots every minute. The results obtained are quite satisfactory, especially in the condition of morning and afternoon.
\end{abstract}

Keywords: background model, intersection bypass ketaping padang, raspberry pi, web camera

\section{PENDAHULUAN}

Kemacetan seringkali terjadi akibat ketidaktahuan pengendara dalam memilih jalur yang akan dilaluinya sehingga terjadi penumpukan kendaraan di wilayah tersebut. Hal ini akan mengakibatkan kerugian waktu dan material.
Berbagai macam cara telah banyak digunakan seperti menggunakan aplikasi waze ataupun google map. Salah satu alternatif solusi adalah dengan menempatkan sistem pemantau lalu lintas yang saling terintegrasi antara alat pemantau dan penyebaran informasi ke publik pada titik-titik simpang yang sering terjadi kemacetan yang harus mempunyai kemampuan untuk memantau kondisi lalu lintas sekitar. 
Penerapan computer vision pada suatu mikrokontroler dan web cam sangat memungkinkan untuk merealisasikan alat pemantau kondisi lalu lintas. Keberhasilan alat pemantau ini sangat bergantung pada penggunaan metode pemprosesan citra terpantau, dari proses akuisisi hingga proses klasifikasi. Hal paling utama adalah cara mendapatkan informasi dari citra tersebut sehingga dapat dijadikan variabel pengenal citra kondisi lalu lintas.

Pemantauan kondisi lalu lintas dengan menggunakan kamera dipengaruhi beberapa faktor, seperti pencahayaan (Kurniawan.,2015) kondisi pagi dan siang hari akan menghasilkan citra obyek dan bayangan obyek sehingga akan menimbulkan gangguan ketika akan dilakukan proses ekstraksi ciri. Faktor berikutnya adalah penempatan kamera yang tidak tepat dapat menghasilkan informasi yang kurang optimal \{Widodo, 2016)

Pada penelitian ini membahas tentang pemantauan lalu lintas menggunakan raspberry pi dengan web camera yang diletakkan pada sisi kiri jalan dalam kondisi statik sehingga citra yang dihasilkan menangkap 2 sisi jalan. Metode yang digunakan menggunakan background subtraction pada ruang hsv (zhao, 2002) dengan menggabungkan variabel simpangan baku (Kurniawan, 2015), mean dan tekstur citra (Li Wei, 2016).

Citra latar ditetapkan dalam 4 kondisi, yaitu pagi, siang, sore dan malam. Penggunaan sampel citra latar ini memudahkan proses penggunaan metode background subtraction (Solichin, 2013), hal ini dikarenakan pendeteksian kepadatan lalu lintas dapat dilakukan dengan pengambilan citra kondisi lalu lintas pada rentang waktu tertentu.

Pada penelitian ini difokuskan pada metode background subtraction pada citra terekam, dengan menggunakan variabel energi dari citra untuk dapat menentukan background kandidat yang tepat sehingga kondisi lalu lintas dapat terdeteksi.

Metode background subtraction diterapkan untuk medeteksi obyek bergerak dengan menggunakan kamera statis pada citra video. Konsep awal dari metode ini memisahkan citra latar yang merepresentasikan sebagai citra yang tidak terdapat obyek bergerak dengan citra yang terdapat obyek bergeraknya sehingga citra hasil berupa citra obyek bergerak. Citra latar harus selalu diperbarui karena untuk menyesuaikan dengan perubahan luminance dan pengaturan geometri yang bervariasi.(Piccardi, 2004)

Metode background subtraction sangat efesien digunakan sebagai algoritma pendeteksi gerak sebagai metode praproses pada sistem pengawasan cerdas (Cheng, 2015)

Salah satu teknik yang sering digunakan dalam metode background subtraction ini adalah menggunakan teknik perbedaan frame

$\mid\left(\right.$ frame $\left._{i}\right)-\left(\right.$ frame $\left._{i-1}\right) \mid>T h$

Estimasi citra latar merupakan pengurangan antara 2 citra tertangkap dari frame terkini dengan frame sebelumnya dan sangat sensitif terhadap nilai thresholdnya (Das, 2014)

Teknik ini sangat rendah kecepatan komputasinya karena hanya membutuhkan 1 frame per detiknya, tetapi kesulitan teknik ini adalah mendapatkan nilai thresholdnya sehingga sulit untuk mendapatkan citra latarnya selain itu juga metode ini sangat dipengaruhi oleh perubahan pencahayaan (Alex,2014) seperti perubahan antara pagi ke siang ke sore lalu ke malam.

\section{METODE PENELITIAN}

Pada Gambar 1 diperlihatkan proses awal penelitian ini, langkah pertama adalah pengambilan gambar dengan menggunakan raspberry pi dan web cam. Pengambilan gambar dilakukan dalam berbagai macam keadaan lalu lintas, keadaan tersebut dianggap sebagai 2 keadaan, yaitu macet dan sepi. Keadaan dianggap macet jika kondisi kendaraan yang melintas dari titik awal hingga titik akhir dari gambar penuh dengan kendaraan, dan dianggap sepi jika sebaliknya. Kondisi tersebut disimpulkan berdasarkan pengamatan langsung. Kemudian pengambilan gambar dilakukan pada 4 keadaan waktu, yaitu pagi (jam 08.00-11.00), siang (12.00-15.00), sore (16.00-18.00), dan malam (19.00 - 23.00), hal ini dilakukan karena keempat keadaan waktu ini memiliki tingkat intensitas cahaya yang berbeda.

Setelah melakukan pengambilan gambar dengan format warna $R G B$ maka langkah selanjutnya adalah memilih citra latar pada masing-masing keadaan waktu, yang akan dipilih sebagai kandidat citra latar. Kemudian dilanjutkan dengan melakukan konversi dari citra ruang warna $R G B$ ke ruang $H S V$, setelah itu dilakukan proses thresholding pada masing-masing kanal $H, S$ dan $V$. Kemudian dilakukan proses penghapusan citra latar pada citra tertangkap (frame image), langkah berikutnya dengan melakukan 2 kali konversi citra dari $H S V$ ke Grayscale dan Grayscale ke Biner untuk menghasilkan citra Hitam dan Putih. Kemudian dilakukan penghapusan obyek yang tidak diinginkan dengan menggunakan Filter Median, dan langkah terakhir adalah masking yang memperlihatkan bahwa sistem 
dapat mendeteksi keadaan lalu lintas yang tertangkap oleh kamera.

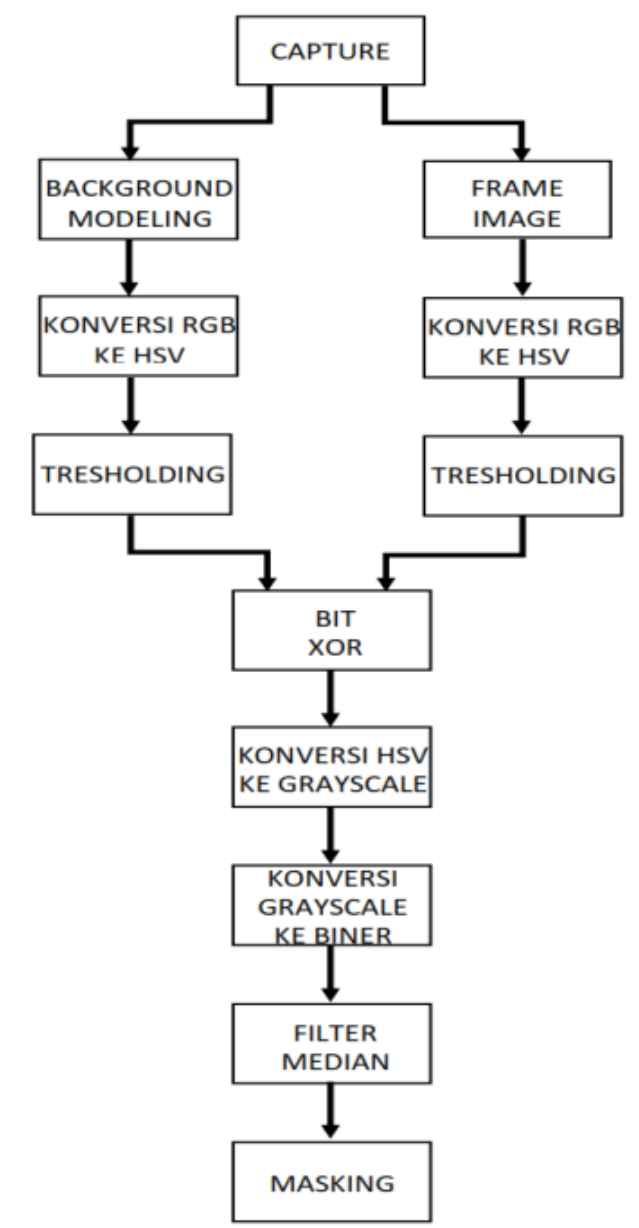

Gambar 1. Diagram alur proses deteksi kondisi lalu lintas dalam 1 kondisi waktu

Untuk menentukan kandidat citra latar digunakan variabel energi dari citra yang tertangkap. Untuk menguji keefektifan variabel energi dalam membedakan keadaan waktu maupun kondisi lalu lintas digunakan metode analisis one way anova. Pada penelitian ini menggunakan perangkat lunak MATLAB dan aplikasi spreadsheet untuk mendeteksi kondisi lalu lintas. Pengujian dilakukan pada kondisi ramai dan sepi dan kondisi waktu pagi, siang, sore dan malam.

\section{HASIL DAN PEMBAHASAN}

Berdasarkan paparan sebelumnya dilakukan beberapa percobaan untuk mendapatkan kondisi citra lalu lintas yang diinginkan, beberapa fungsi Matlab dan aplikasi spreadsheet digunakan dalam percobaan ini.

\subsection{Background Modeling}

Pada tahap ini digunakan metode uji ralat dan galat sehingga mendapatkan citra latar terpilih. Pada tahap awal dihasilkan kandidat citra latar (frame $i$-frame $i$ 1), dengan berdasar pada keadaan sepi di kondisi waktu pagi, siang, sore, dan malam, seperti terlihat pada gambar 2 .

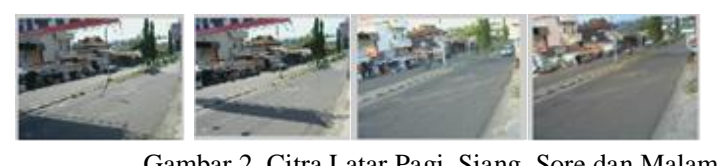

Langkah selanjutnya pendeteksian kondisi lalu lintas dengan memilah citra latar dari citra asli sehingga kondisi lalu lintas dapat terdeteksi

\subsection{Background Subtraction}

Sebelum melakukan proses pemilahan citra tertangkap, maka dilakukan praproses citra dengan mengkonversi citra ke ruang $H S V$ dan melakukan thresholding otomatis masing-masing kanal Hue, saturation dan value, seperti terlihat pada Tabel 1. Proses yang sama dilakukan pada semua citra tertangkap pada kondisi sepi dan ramai di keadaan waktu pagi, siang, sore dan malam, maka hasil yang didapatkan adalah seperti terlihat pada Tabel 2 .

Ketika citra tertangkap dalam kondisi ramai, seperti terlihat pada gambar 3 maka ada 2 kemungkinan penyebabnya, yaitu lampu lalu lintas berwarna merah (harus berhenti) atau ada penyebab lain yang mengakibatkan terjadi penumpukan kendaraan, jika citra tertangkap secara terus menerus mendeteksi kondisi seperti ini maka dapat dikondisikan lalu lintas dalam keadaan macet

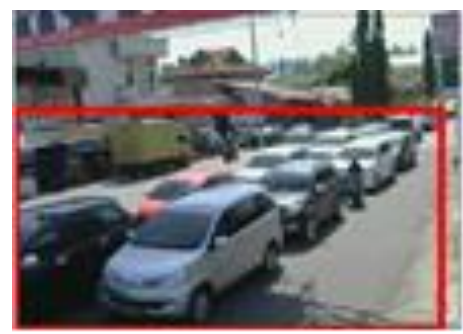

Gambar 3. Citra tertangkap dalam kondisi ramai

Pada Tabel 3, diperlihatkan metode yang digunakan tidak dapat mendeteksi dengan baik ketika citra tertangkap pada kondisi sore, hal ini disebabkan oleh pengaruh bayangan yang terlalu panjang sehingga sulit untuk dihilangkan yang akibatnya dianggap sebagai obyek. Pada kondisi tersebut citra akan selalu terdeteksi dalam keadaan ramai.

Jika citra latar yang digunakan pada kondisi waktu yang berbeda maka sistem akan mendeteksi keadaan yang salah, seperti terlihat pada gambar 4 yang 
734 Jurnal Teknologi Informasi dan Ilmu Komputer (JTIIK), Vol. 5, No. 6, November 2018, hlm. 731-736

menggunakan citra latar malam dengan citra tertangkap pada kondisi waktu pagi.

Tabel 1. Image Processing Kondisi Lalu Lintas

\begin{tabular}{|c|c|}
\hline PROSES & $\begin{array}{c}\text { CITRA LATAR DAN CITRA } \\
\text { TERTANGKAP }\end{array}$ \\
\hline & 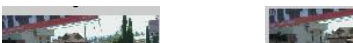 \\
\hline \multicolumn{2}{|l|}{ BACA CITRA } \\
\hline \multicolumn{2}{|l|}{$\begin{array}{l}\text { KONVERSI RGB } \\
\text { KE HSV }\end{array}$} \\
\hline \multicolumn{2}{|l|}{$\begin{array}{c}\text { THRESHOLDIN } \\
\text { G }\end{array}$} \\
\hline \multicolumn{2}{|l|}{ OPERASI XOR } \\
\hline \multicolumn{2}{|l|}{$\begin{array}{l}\text { KONVERSI HSV } \\
\text { KE GRAY }\end{array}$} \\
\hline \multirow{2}{*}{\multicolumn{2}{|c|}{$\begin{array}{l}\text { KONVERSI } \\
\text { GRAY KE } \\
\text { BINER }\end{array}$}} \\
\hline & \\
\hline \multirow{2}{*}{\multicolumn{2}{|c|}{$\begin{array}{l}\text { FILTER } \\
\text { MEDIAN }\end{array}$}} \\
\hline & \\
\hline OPERASI & \\
\hline MORFOLOGI & \\
\hline MASKING & 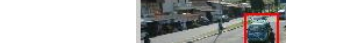 \\
\hline
\end{tabular}

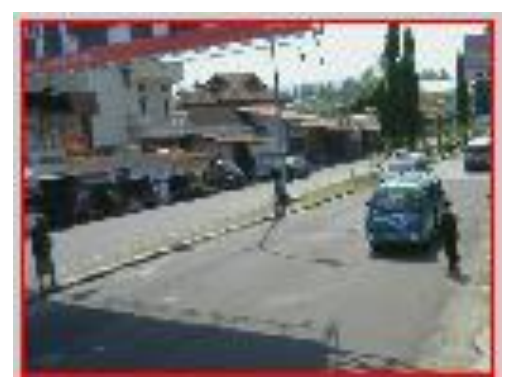

Gambar 4. Citra terdeteksi

Karena hal tersebut maka diperlukan metode tambahan pada sistem agar dapat mengenali kondisi waktu citra tertangkap sehingga sistem dapat mengkondisikan citra latar sesuai dengan waktu citra tertangkap.
Salah satu variabel yang dapat digunakan adalah dengan menggunakan variabel energi dari citra tertangkap. Untuk memastikan bahwa variabel energi dapat digunakan untuk mengenali kondisi waktu dari citra tertangkap maka dilakukan pengujian dengan menggunakan anova one way.

\begin{tabular}{cccc}
\multicolumn{4}{c}{ Tabel 2. Pengujian Deteksi Kondisi Lalu Lintas } \\
\hline NO & $\begin{array}{c}\text { KEADAAN } \\
\text { WAKTU }\end{array}$ & $\begin{array}{c}\text { KONDISI } \\
\text { LALU }\end{array}$ & KETERANGAN \\
\hline 1. & PAGI & SEPI & TERDETEKSI \\
2. & PAGI & 1 MOBIL & TERDETEKSI \\
3. & PAGI & 2 MOBIL & TERDETEKSI \\
4. & PAGI & RAMAI & TERDETEKSI \\
5. & SIANG & SEPI & TERDETEKSI \\
6. & SIANG & 1 MOBIL & TERDETEKSI \\
7. & SIANG & 2 MOBIL & TERDETEKSI \\
8. & SIANG & RAMAI & TERDETEKSI \\
9. & SORE & SEPI & BANYAK NOISE \\
10. & SORE & 1 MOBIL & BANYAK NOISE \\
11. & SORE & 2 MOBIL & BANYAK NOISE \\
12. & SORE & RAMAI & TERDETEKSI \\
13. & MALAM & SEPI & TERDETEKSI \\
14. & MALAM & 1 MOBIL & TERDETEKSI \\
15. & MALAM & 2 MOBIL & TERDETEKSI \\
16. & MALAM & RAMAI & TERDETEKSI \\
\hline & & &
\end{tabular}

Tabel 3. Nilai Energi Pada Perbedaan Waktu pada kondisi macet

\begin{tabular}{cccc}
\hline pagi & siang & Sore & malam \\
\hline 0,13845 & 0,11622 & 0,22648 & 0,26427 \\
0,13682 & 0,13625 & 0,2126 & 0,23502 \\
0,10996 & 0,13509 & 0,21722 & 0,23572 \\
0,11308 & 0,13028 & 0,20786 & 0,23472 \\
0,11495 & 0,13411 & 0,21299 & 0,23953 \\
\hline
\end{tabular}

Uji Anova One Way pada tabel 3 adalah sebagai berikut :

Hipotesa (Ho) : Energi citra pada waktu pagi, siang, sore dan malam pada keadaan lalu lintas macet adalah sama.

Tabel 4. Uji ANOVA One way

\begin{tabular}{lcccccc}
\hline $\begin{array}{l}\text { Source of } \\
\text { Variation }\end{array}$ & $S S$ & $d f$ & $M S$ & $F$ & $\begin{array}{c}P- \\
\text { value }\end{array}$ & F crit \\
\hline Between & 0,054037 & 3 & 0,018012 & 153,8638 & 5,22 & 3,238872 \\
Groups & & & & & & \\
Within & 0,001873 & 16 & 0,000117 & & & \\
Groups & & & & & &
\end{tabular}


Pada tabel 4 diperlihatkan bahwa nilai $\mathrm{F}>$ Fcrit yang berarti Ho ditolak berarti bahwa Nilai Energi tiap waktu adalah berbeda.

Pada kondisi sepi juga menghasilkan kesimpulan yang sama.

\begin{tabular}{crr}
\multicolumn{3}{c}{ Tabel 5. Nilai Energi Pada Perbedaan } \\
Keadaan Lalu Lintas Pada Waktu Pagi \\
\hline No. & Macet & \multicolumn{2}{c}{ Sepi } \\
\hline 1. & 0,10934 & 0,13845 \\
2. & 0,10888 & 0,13682 \\
3. & 0,11045 & 0,10996 \\
4. & 0,11264 & 0,11308 \\
5. & 0,11312 & 0,11495 \\
6. & 0,10303 & 0,11622 \\
\hline
\end{tabular}

Uji Anova One Way pada tabel 3 adalah sebagai berikut :

Hipotesa (Ho) : Energi citra pada keadaan lalu lintas macet dan sepi pada waktu pagi adalah sama

Uji Anova One Way pada tabel 5 terlihat pada tabel 6

Pada tabel 6 diperlihatkan bahwa nilai $\mathrm{F}>$ Fcrit yang berarti Ho ditolak berarti bahwa Nilai Energi tiap keadaan lalu lintas macet atau sepi pada waktu pagi adalah berbeda.

Tabel 6. Uji ANOVA

\begin{tabular}{ccccccc}
\hline $\begin{array}{c}\text { Source of } \\
\text { Variation }\end{array}$ & $S S$ & $d f$ & $M S$ & $F$ & $P$-value & F crit \\
\hline $\begin{array}{c}\text { Between } \\
\text { Groups }\end{array}$ & 0,000432 & 1 & 0,000432 & 5,009054 & 0,049163 & 4,964603 \\
Within & & & & & & \\
Groups & 0,000863 & 10 & $8,63 \mathrm{E}-05$ & & & \\
& & & & & & \\
Total & 0,001295 & 11 & & & & \\
\hline
\end{tabular}

Pengujian pada waktu, siang, sore dan malam menghasilkan kesimpulan yang sama.

\section{SIMPULAN}

Pada penelitian ini dapat disimpulkan bahwa pendeteksian citra lalu lintas dengan citra latar terpilih dapat mendeteksi kondisi lalu lintas pada waktu pagi, siang, dan malam, tetapi pada kondisi sore hari menghasilkan deteksi yang hampir sama pada keadaan lalu lintas macet ataupun sepi diakibatkan pengaruh bayangan panjang.
Penggunaan variabel energi citra tertangkap dapat digunakan untuk membedakan citra latar terpilih pada waktu pagi, siang, sore dan malam, karena perbedaan citra latar menghasilkan deteksi yang salah.

\section{DAFTAR PUSTAKA}

ACHMAD S., AGUS H., (2013), Metode Background Subtraction untuk Deteksi Obyek Pejalan Kaki pada Lingkungan Statis, Prosiding Seminar Nasional Aplikasi Teknologi Informasi (SNATI), Yogyakarta ISSN: 1907 - 5022 Hal B-1

ALEX D STALIN, DR. AMITABH W., (2014), BSFD: Background Subtraction Frame Difference Algorithm For Moving Object Detection And Extraction, Journal of Theoretical and Applied Information Technology 28th February 2014. Vol. 60 No.3

CHENG FAN-CHIEH., BO-HAO C., AND SHIHCHIA H, (2015), A Hybrid Background Subtraction Method with Background and Foreground Candidates Detection, ACM Trans. Intell. Syst. Technol. 7, 1, Article 7, 14.

DAS, DEEPJOY AND DR. SARAT S., (2014), Implementation And Performance Evaluation Of Background Subtraction Algorithms, International Journal on Computational Sciences \& Applications (IJCSA) Vol.4, No.2,

FREDDY K., HARUNO S., OKTO D., (2015) Pendeteksian Kepadatan Lalu-lintas dengan Menggunakan Simpangan Baku Histogram Citra Jalan, Prosiding Seminar Nasional ReTII, 1-8

GIANTO W., RAHMADWATI, PURNOMO B.S., FACHRUL K., (2016), Analisa Penempatan Kamera CCTV Menggunakan Metode Simple Additive Weighting (SAW) Untuk Smart Monitoring, MATICS : Jurnal Ilmu Komputer dan Teknologi Informasi ISSN : 1978-161X(p); 2477-2550(e) Volume 8, No. 2, 44-47

MING ZHAO, JIAJUN BU, CHUN CHEN, Robust background subtraction in HSV color space, Proceedings Volume 4861, Multimedia Systems and Applications V, (2002).

PICCARDI MASSIMO, (2004), Background subtraction techniques: a review, IEEE International Conference on Systems, Man and Cybernetics 
Halaman ini sengaja dikosongkan 